\title{
Fístula broncoesofágica secundaria a aspergilosis pulmonar
}

\section{Bronchoesofageal Fistula Secondary to Pulmonary Aspergillosis}

Antonio M. Caballero-Mateos, ${ }^{1 *}$ (1) Mercedes López de Hierro-Ruiz, ${ }^{2}$ Eduardo Redondo-Cerezo. ${ }^{2}$ (이

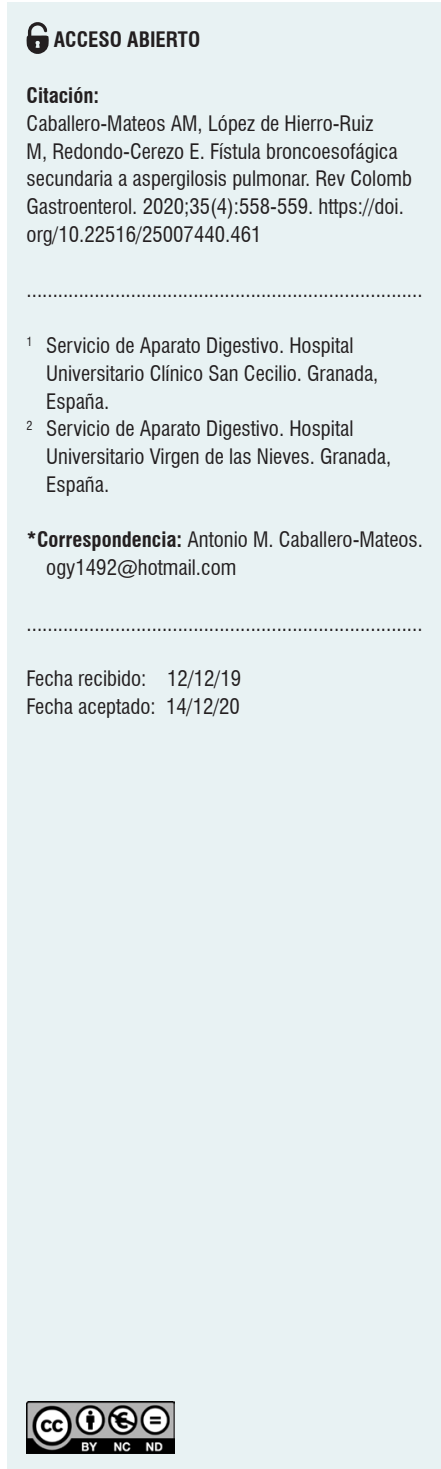

\section{Señor Editor:}

Un varón de 61 años fue ingresado en nuestro centro con clínica de disnea y disfagia a sólidos y a líquidos de dos semanas de evolución. Mostraba palidez mucocutánea en la exploración y los datos analíticos solo resaltaban una ligera anemia (hemoglobina $[\mathrm{Hb}]$ : $12,5 \mathrm{~g} / \mathrm{dL}$ ). Estaba diagnosticado hacía dos meses de leucemia mieloblástica aguda y posteriormente inició el tratamiento con idarubicina.

Se realizó una endoscopia digestiva alta (EDA) en la que se observó una lesión esofágica amarillenta y blanquecina de $0,8 \mathrm{~cm}$ en torno a los 29 centímetros de la arcada dental, que no aparentaba originarse en la mucosa esofágica ya que presentaba un movimiento independiente (Figura 1) y que sugería la presencia de una fístula esofágica. Se realizó una tomografía axial computarizada (TAC) que confirmó el diagnóstico de fístula broncoesofágica asociada con una masa mediastínica (Figura 2). Una broncoscopia posterior mostró una masa endobronquial obliterante y necrótica, con pseudomembranas de aspecto maligno.

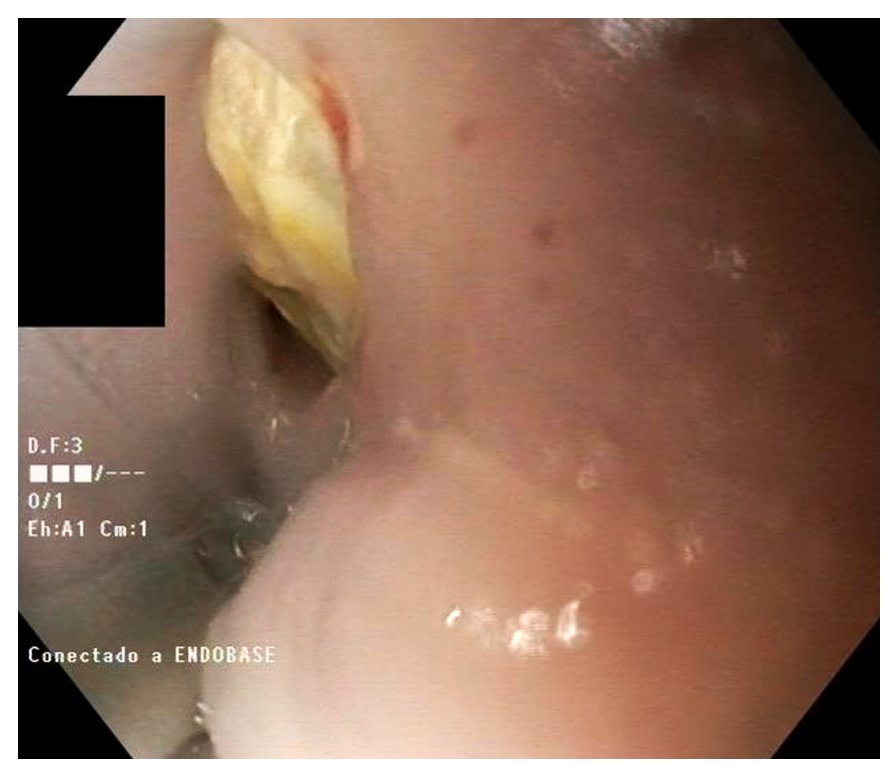

Figura 1. Imagen endoscópica del orificio fistuloso en el esófago. 
Se realizó un lavado broncoalveolar (BAL) y se tomaron biopsias. La masa fue resecada quirúrgicamente. Durante la intervención se realizó una nueva EDA que consiguió cerrar la fístula mediante un clip over-the-scope $\left(\mathrm{Ovesco}^{\circledast}\right)$ (Figura 3). El estudio anatomopatológico informó de un tejido necrótico y de granulación, así como grandes colonias de hifas de Aspergillus, con ausencia de células malignas. El BAL fue positivo a la prueba de galactomanano (I > 4). Infortunadamente, el paciente pereció dos días después de la intervención.

La aspergilosis es un hallazgo infrecuente observado en contextos como inmunosupresión, tratamientos quimioterápicos contra trastornos hematológicos o en trasplantados (1). La formación de fístulas es una complicación rara de la aspergilosis pulmonar (2), y las broncopleurales son las

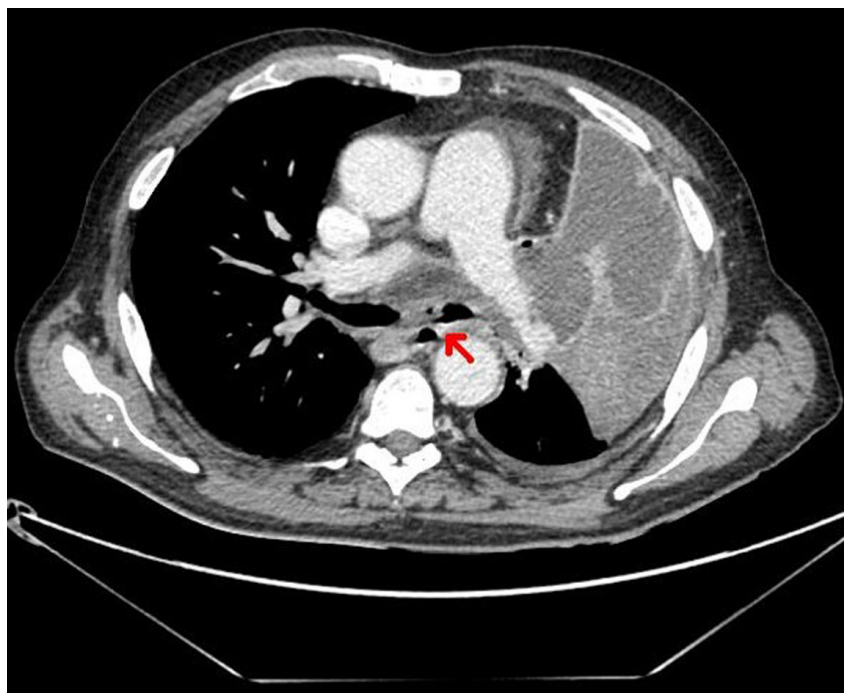

Figura 2. Imagen de TAC que muestra la comunicación entre el esófago y el bronquio asociada con una masa mediastínica. más descritas. El uso del Ovesco se ha desarrollado en la última década para procedimientos endoscópicos como sangrado gastrointestinal, fístulas o perforaciones, con una tasa de éxito clínico entre el 64 \% y el 91,7 \% (3-5). La presencia de fístulas crónicas o radioterapia previa son frecuentes en los casos en los que el tratamiento fracasó. Los riesgos de su uso (sangrado, perforación o aspiración) son infrecuentes cuando el uso del instrumental es correcto. Se han descrito casos de fístulas traqueoesofágicas tratadas exitosamente con Ovesco, pero no de fístulas broncoesofágicas. Esta última es un hallazgo excepcional y poco reportado, que en este caso fue resuelto mediante un clip Ovesco en una primera instancia, aunque en el contexto clínico del paciente no fue suficiente debido a que no hubo la oportunidad de comenzar un tratamiento antifúngico específico.

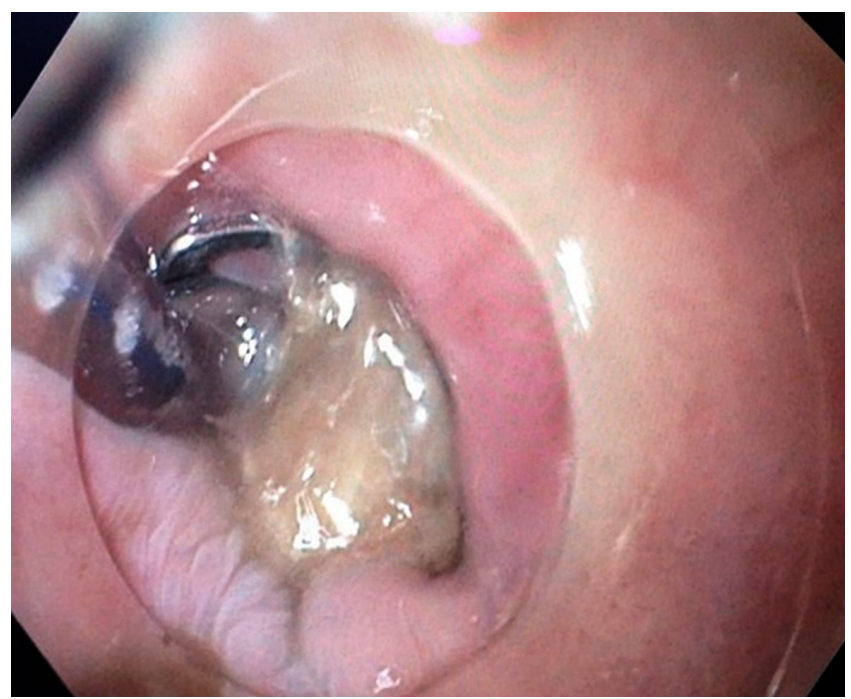

Figura 3. Imagen endoscópica luego del cierre del orificio fistuloso con el clip Ovesco.

\section{REFERENCIAS}

1. Yu Y, Zhu C, Qian X, Gao Y. Tracheoesophageal fistula induced by invasive pulmonary aspergillosis. Annals of Translational Medicine. 2016;4(18):345. https://doi.org/10.21037/atm.2016.09.16

2. Mineur P, Ferrant A, Wallon J, Otte JB, Michaux JL. Bronchoesophageal fistula caused by pulmonary aspergillosis. Eur J Respir Dis. 1985;66(5):360-6.

3. Goenka MK, Rai VK, Goenka U, Tiwary IK. Endoscopic Management of Gastrointestinal Leaks and Bleeding with the Over-the-Scope Clip: A Prospective Study. Clin Endosc. 2017;50(1):58-63.

https://doi.org/10.5946/ce.2016.028
4. Morrell DJ, Winder JS, Johri A, Docimo S, Juza RM, Witte SR, Alli VV, Pauli EM. Over-the-scope clip management of non-acute, full-thickness gastrointestinal defects. Surg Endosc. 2020;34(6):2690-2702. https://doi.org/10.1007/s00464-019-07030-3

5. Mosquera-Klinger G, Torres-Rincón R, Jaime-Carvajal J. Endoscopic closure of gastrointestinal perforations and fistulas using the Ovesco Over-The-Scope Clip system at a tertiary care hospital center. Rev Gastroenterol Mex. 2019;84(2):263-266. https://doi.org/10.1016/j.rgmx.2018.10.004 